\title{
Substituição parcial do concentrado por feno de tifton na alimentação de bezerros Girolando ${ }^{1}$
}

\author{
Natália Jamylle Germano Gomes ${ }^{2}$, Severino Gonzaga $\mathrm{Neto}^{2}$, Carla Giselly de Souza ${ }^{3}$, Raimundo \\ Ribeiro Ferreira ${ }^{2}$, Marcelo de Oliveira Alves Rufino ${ }^{2}$, Carlos Augusto de Almeida Targino \\ Alcoforado ${ }^{2}$
}

\begin{abstract}
Resumo: Na criação de bovinos leiteiros, a fase mais crítica é o período entre o nascimento e a desmama, onde a taxa de mortalidade pode ser elevada a depender dos manejos sanitário e nutricional. Objetivou-se avaliar o desenvolvimento de bezerros Girolando do nascimento à desmama em função de 2 tipos de dietas sólidas. Foram utilizados 8 bezerros da raça Girolando com idade média de um mês, pertencentes ao Setor de Bovinocultura de Leite do Departamento de Zootecnia/CCA/UFPB. Os animais foram alojados em bezerreiros tipo argentino, onde cada animal disponha de casinha individual. Os tratamentos consistiram em aleitamento artificial com fornecimento de 4 litros de sucedâneo diariamente e dieta sólida durante 90 dias. A dieta sólida consistiu em 2 tipos de alimentação baseadas em concentrado e volumoso. A Dieta 1 consistia em $100 \%$ concentrado em forma de ração peletizada, a Dieta 2 em volumoso na forma de feno de Tifton moído e ração peletizada 50:50. As sobras das dietas fornecidas foram pesadas diariamente nos períodos manhã e tarde. Cada animal passou 90 dias em avaliação. As avaliações foram quinzenais. Eram aferidos parâmetros de peso vivo, perímetro torácico e altura de cernelha. Após aferição era calculado o ganho de peso diário e mensal. Foi utilizado um delineamento inteiramente casualizado (DIC) em parcelas subdivididas. O peso vivo dos animais aumentou linearmente nas duas dietas, não havendo diferença significativa $(\mathrm{P}<0,001)$ entre quilos ganhos. $O$ peso vivo e altura de cernelha não apresentaram influência $(P<0,001)$ entre as Dietas 1 e 2 . Houve diferença significativa $(P<0,001)$ para perímetro torácico na Dieta 1, em função dos dias. A substituição de $50 \%$ do concentrado por feno não afetou o desenvolvimento de bezerros no período de 30 a 90 dias de idade.
\end{abstract}

Palavras-chave: bovino de leite; ganho de peso; perímetro torácico.

\section{Partial substitution from concentrate to tifton hay in feeding Girolando calves}

\begin{abstract}
The objective of this study was to evaluate the development of Girolando calves from birth to weaning due to two solid diets types. Eight Girolando calves with an average age of one month, belonging to the Department of Animal Husbandry of the Department of Animal Science / CCA / UFPB, were used. The animals were housed in Argentinean type houses, where each animal has an individual house. The treatments consisted of artificial feeding with 4 substitute daily liters and a solid diet for 90 days. The solid diet consisted of 2 types of food based on concentrate and bulky. Diet 1 consisted of $100 \%$ concentrate in the pelleted feed form, the Diet 2 bulk in the form of milled Tifton hay and 50:50 pelleted feed. Leftover diets provided were weighed daily in the morning and afternoon periods. Each animal spent 90 days under evaluation. The evaluations were biweekly. Measured parameters of live weight, thoracic perimeter and withers height were measured. After gauging, the daily and monthly weight gain was calculated. A completely randomized design (DIC) was used in subdivided plots. The live weight of the animals increased linearly in both diets, and there was no significant difference ( $\mathrm{P}$ $<0.001)$ between pounds gained. The live weight and withers height had no influence $(\mathrm{P}<0.001)$ between Diets 1 and 2. There was a significant difference $(\mathrm{P}<0.001)$ for the thoracic perimeter in Diet 1 , as a function of days. The replacement of $50 \%$ of the concentrate per hay did not affect the calves development in the period from 30 to 90 days of age.
\end{abstract}

Keywords: bovine milk; weight gain; thoracic perimeter.

\footnotetext{
${ }^{1}$ Submetido em 14/08/2018 a aprovado em 10/11/2019;

${ }^{2}$ Departamento de Zootecnia, Universidade Federal da Paraíba, Areia, Paraíba, Brasil; E-mail: germanojamylle@gmail.com; sgonzaganeto@gmail.com - ORICD: 0000-0003-4220-4071; $\quad$ rdoribeiro.rrf@gmail.com - ORICD: 0000-0003-4239-2383; moarufino@gmail.com - ORICD: 0000-0003-1725-9396; catargino@ hotmail.com;

${ }^{3}$ Programa de Pós-Graduação em Zootecnia, Universidade Federal Rural de Pernambuco, Recife, Pernambuco, Brasil; E-mail: carlaxlsouza@yahoo.com.br - ORICD: 0000-0003-4701-0954.
}

Agropecuária Técnica, Areia-PB, v. 40, n. 1-2, p. 40-47, 2019

https://doi.org/10.25066/agrotec.v40i1-2.42161 


\section{Introdução}

No sistema de criação de bovinos leiteiros, o período entre o nascimento e a desmama é a fase mais crítica, quando a taxa de mortalidade pode ser elevada dependendo do manejo sanitário e nutricional dos animais. Fatores como genética, nutrição e sanidade são essenciais dentro de um sistema de criação de bovinos leiteiros para obtenção do potencial produtivo. Toda essa preocupação deve-se iniciar na criação dos bezerros, já que o futuro de qualquer exploração leiteira depende do adequado sistema de criação (Ferreira et al., 2009).

Ao nascimento o abomaso é maior que os outros compartimentos e o rúmen não é desenvolvido. $\mathrm{O}$ fornecimento de alimentos sólidos, além da dieta líquida, estimula o surgimento e crescimento do rúmen e outros compartimentos gástricos, acelerando a transição da fase pré-ruminal para a de ruminante funcional (Ferreira et al., 2009). Normalmente bezerros criados à pasto tem maiores chances de desenvolver a musculatura do rúmen, são mais precoces no desenvolvimento do processo de fermentação ruminal que os animais criados em estabulação completa. Essa prática (criação à pasto) também reduz o custo de criação por redução no custo de mão de obra e das instalações necessárias para a manutenção (Oliveira e Nogueira, 2006).

A taxa de ganho de peso de bezerros é limitada pelo consumo voluntário adequado de energia, aliado a isso existe ainda uma decisão de ordem econômica, em que fatores como o custo da alimentação envolvida, o produto final desejado e a taxa de retorno do capital investido devem ser minuciosamente considerados (Oliveira e Nogueira, 2006). Deve-se haver, entretanto, um limite mínimo de crescimento para permitir que ocorra o desenvolvimento genético do animal sem que prejudique sua vida produtiva.

Deste modo, podemos definir crescimento como a variação dos parâmetros que avaliam o esqueleto e o desenvolvimento somático, como a variação do ganho de peso. $\mathrm{O}$ crescimento corporal é regulado por fatores extrínsecos ou ambientais e por fatores intrínsecos ou orgânicos.
Normalmente o crescimento é definido como a produção de novas células, mas, por ser avaliado sempre em termos de massa tem-se de considerar, também, o aumento celular, ou seja, a hipertrofia (Owens et al., 1993).

Assim, objetivou-se com o presente estudo avaliar o desenvolvimento de bezerros Girolando do nascimento à desmama em função de dietas sólidas.

\section{Material e Métodos}

O estudo foi realizado no período de junho a novembro de 2017 no setor de Bovinocultura de Leite, do Centro de Ciências Agrárias (CCA), da Universidade Federal da Paraíba (UFPB) Campus II, Areia - PB, localizado na Microrregião do Brejo Paraibano que tem uma altitude de $618 \mathrm{~m}$, precipitação pluvial média de $1400 \mathrm{~mm}$ por ano e com temperaturas que vão de $12^{\circ} \mathrm{C}$ a $31^{\circ} \mathrm{C}$ (Gondim e Fernandes, 1980). Segundo dados da Estação Agrometereológica do Centro de Ciências Agrárias a temperatura média variou de $21,9^{\circ} \mathrm{C}$ a $23^{\circ} \mathrm{C}$ durante os meses da avaliação.

Foram utilizados 8 bezerros, três machos e cinco fêmeas da raça Girolando, com média de peso ao nascimento de $35,15 \pm 10,0 \mathrm{~kg}$, pertencentes ao Setor de Bovinocultura de Leite do Departamento de Zootecnia/CCA/UFPB. Os bezerros entraram para o experimento com um mês de idade, quando já apresentavam uma independência para ingestão de alimentos sólidos e passado por vermifugação com carrapaticida $\left(\right.$ Topline $\left.^{\circledR}\right)$, mensalmente refeita.

Os animais foram alojados em bezerreiro tropical ou argentino (sombrite sentido NorteSul) onde cada animal dispõe de casinhas individuais (sentido Leste-Oeste), com coleiras que os permite acesso à água, pasto, concentrado, feno e abrigo e neste sistema permaneceram três meses de experimento. Este tipo de sistema possibilita maior radiação na instalação facilitando a desinfecção e diminuição de umidade, minimizando assim a proliferação de microrganismos patogênicos causadores de doenças. 
Cada animal era contido por uma coleira e uma corrente (1,5 metros) ligados por um fio de aço com cerca de 10 metros de comprimento sustentado por duas estacas. A área total do sombrite foi de $96 \mathrm{~m}^{2}$, sendo 32 metros de comprimento e 3 metros de largura disponibilizada para os oito animais. Os animais tiveram acesso a área de sombreamento e de sol, ocorrendo interação com os outros animais, sendo possível haver contato físico com o outro.

Os tratamentos consistiram em aleitamento artificial com fornecimento de quatro litros de sucedâneo Sprayfo $^{\circledR}$ (Tabela 1) diariamente durante os 90 dias de experimento, fazendo a diluição para cada $100 \mathrm{~g}$ de sucedâneo utilizado em um litro de água, a água foi aquecida de 38$39^{\circ} \mathrm{C}$ para melhor homogeneização do produto, e assim fornecida em média a temperatura de $35^{\circ} \mathrm{C}$. $\mathrm{O}$ fornecimento do leite foi dividido em duas porções ao dia, 2 litros de leite pela manhã às 7:30 horas e 2 litros de leite na parte da tarde às 14:30 horas.

A dieta sólida dos animais consistiu em dois tipos de alimentação baseadas em concentrado e volumoso (Tabela 2 ) ofertadas em comedouros de plástico.

A Dieta 1 consistia em $100 \%$ concentrado ofertado em forma de ração peletizada, a Dieta 2 em volumoso na forma de feno de Tifton moído e ração peletizada com proporção de 50:50, onde o volumoso foi triturado e misturado ao peletizado de forma homogênea antes de cada oferta (Tabela $3)$.

A divisão das dietas foi feita a partir da entrada de cada animal, onde o primeiro recebeu a Dieta 1, o segundo a Dieta 2, o terceiro a Dieta 1, e assim até o último animal. As dietas foram pesadas diariamente sempre que fornecidas tanto no período da manhã quanto a tarde e permitiam uma disponibilidade de 50 a $100 \mathrm{~g}$ de sobras por animal. Inicialmente foi ofertado $200 \mathrm{~g}$ da dieta para cada animal, já que estes estavam em fase de crescimento não foi estimada uma quantidade exata de alimento para todo o experimento, então a medida que os animais diminuíssem as sobras era aumentado $100 \mathrm{~g}$ em sua dieta.
Tabela 1 Composição química do alimento substituto do leite para alimentação animal, Sprayfo Violeta $\mathrm{SSP}^{\circledR}$

\begin{tabular}{|c|c|}
\hline Componente & Quantidade \\
\hline Proteína Bruta $\left(\mathrm{g} \mathrm{kg}^{-1}\right)$ & 200,0 \\
\hline Extrato Etéreo $\left(\mathrm{kg}^{-1}\right)$ & 160,0 \\
\hline Lactose $\left(\mathrm{g} \mathrm{kg}^{-1}\right)$ & 470,0 \\
\hline Matéria Mineral $\left(\mathrm{g} \mathrm{kg}^{-1}\right)$ & 77,0 \\
\hline Matéria Fibrosa $\left(\mathrm{mg} \mathrm{kg}^{-1}\right)$ & 500 \\
\hline Umidade $\left(\mathrm{g} \mathrm{kg}^{-1}\right)$ & 35 \\
\hline Fósforo $\left(\mathrm{mg} \mathrm{kg}^{-1}\right)$ & 5000 \\
\hline Cálcio min $\left(\mathrm{mg} \mathrm{kg}^{-1}\right)$ & 7000 \\
\hline Cálcio max (mg kg$\left.{ }^{-1}\right)$ & 9000 \\
\hline Energia Metabolizável $\left(\mathrm{kcal} \mathrm{kg}^{-1}\right)$ & 4.178 \\
\hline Betaína $\left(\mathrm{mg} \mathrm{kg}^{-1}\right)$ & 600 \\
\hline Cebalto $\left(\mathrm{mg} \mathrm{kg}^{-1}\right)$ & 1 \\
\hline FDA $\left(\mathrm{mg} \mathrm{kg}^{-1}\right)$ & 1000 \\
\hline Vitamina A (UI kg-1) & 25.000 \\
\hline Vitamina D3 (UI kg $\left.{ }^{-1}\right)$ & 5.000 \\
\hline Vitamina $\mathrm{E}\left(\mathrm{mg} \mathrm{kg}^{-1}\right)$ & 80 \\
\hline Vitamina $\mathrm{K}\left(\mathrm{mg} \mathrm{kg}^{-1}\right)$ & 4 \\
\hline Vitamina $\mathrm{C}\left(\mathrm{mg} \mathrm{kg}^{-1}\right)$ & 80 \\
\hline Vitamina B1 $\left(\mathrm{mg} \mathrm{kg}^{-1}\right)$ & 6 \\
\hline Viatmina B2 $\left(\mathrm{mg} \mathrm{kg}^{-1}\right)$ & 6 \\
\hline Vitamina B6 $\left(\mathrm{mg} \mathrm{kg}^{-1}\right)$ & 4 \\
\hline Vitamina B12 $\left(\mathrm{mcg} \mathrm{kg}^{-1}\right)$ & 20 \\
\hline Ácido Fólico (mg kg-1) & 0,45 \\
\hline Niacina $\left(\mathrm{mg} \mathrm{kg}^{-1}\right)$ & 40 \\
\hline Biotina $\left(\mathrm{mg} \mathrm{kg}^{-1}\right)$ & 0,1 \\
\hline Ácido Pantotêncico $\left(\mathrm{mg} \mathrm{kg}^{-1}\right)$ & 15 \\
\hline Cobre $\left(\mathrm{mg} \mathrm{kg}^{-1}\right)$ & 8 \\
\hline Ferro $\left(\mathrm{mg} \mathrm{kg}^{-1}\right)$ & 90 \\
\hline Magnésio (mg kg-1) & 300 \\
\hline Manganês (mg kg-1) & 45 \\
\hline Selênio $\left(\mathrm{mg} \mathrm{kg}^{-1}\right)$ & 0,2 \\
\hline Zinco $\left(\mathrm{mg} \mathrm{kg}^{-1}\right)$ & 85 \\
\hline
\end{tabular}


Tabela 2 Composição das dietas

\begin{tabular}{lccc}
\hline & Sucedâneo & Peletizado & Feno de Tifton \\
Dieta 1 & $4 \mathrm{~L}$ & $100 \%$ & - \\
Dieta 2 & $4 \mathrm{~L}$ & $50 \%$ & $50 \%$ \\
\hline
\end{tabular}

Tabela 3 Composição bromatológica dos ingredientes das dietas à base de concentrado Peletizado e Feno de Tifton em porcentagem de matéria seca

\begin{tabular}{lcc}
\hline Componente & Peletizado & Feno Tifton \\
\hline MS (\%) & 90,40 & 88,94 \\
MM & 4,22 & 6,40 \\
PB & 18,00 & 9,69 \\
EE & 2,50 & 1,55 \\
FDN & 16,48 & 70,09 \\
FDA & 52,58 & 32,66 \\
\hline
\end{tabular}

MS: Matéria Seca; MM: Matéria Mineral; PB: Proteína Bruta; EE: Extrato Etéreo; FDN: Fibra em Detergente Neutro; FDA: Fibra em Detergente Ácido. Adaptado de Valadares Filho (2015) e DuRancho Nutrição Animal.

O período experimental total foi de 158 dias. A entrada dos animais aconteceu trinta dias após o nascimento, onde, cada animal passou 90 dias em avaliação. Durante a avaliação quinzenalmente os animais eram direcionados a um piquete onde eram aferidos parâmetros de peso vivo $(\mathrm{PV})$, perímetro torácico $(\mathrm{PT})$ e altura de cernelha (AC). O peso dos animais foi medido em balança (Cauduro ${ }^{\circledR}$ ) estimada para $2.000 \mathrm{~kg}$ e sua circunferência torácica e altura de cernelha aferida com fita métrica graduada em centímetros.

Foi acompanhado o peso dos animais do nascimento à desmama, que ocorreu por volta dos 90 dias de vida após o nascimento ou até $100 \mathrm{~kg}$ de peso vivo. Após a análise do peso vivo $(\mathrm{kg})$, perímetro torácico $(\mathrm{cm})$ e altura de cernelha $(\mathrm{cm})$, foi calculado o ganho mensal e diário de peso.

Os dados referentes às variáveis peso vivo, altura de cernelha e perímetro torácico foram analisados adotando-se o modelo em delineamento inteiramente casualizado (DIC), no esquema de parcelas subdivididas, em que a Dietas constituíram as parcelas e os Dias de amostragem as subparcelas, segundo o modelo estatístico:

Yijk $=\mu+$ Dietas i + Resíduo a(ik) + Dias $(j)+$ Dietas * Dias (ij) + Resíduo b (ijk)

Os resultados foram submetidos à análise de variância e de regressão utilizando-se o procedimento GLM do Statistical Analisis
System (SAS, 2010). A escolha do modelo foi feita com base no coeficiente de determinação e na significância observada, a $5 \%$ de probabilidade.

\section{Resultados e Discussão}

Dentre as mensurações feitas de peso vivo, altura de cernelha e perímetro torácico, a única que apresentou diferença significativa $(\mathrm{P}<0,001)$ foi perímetro torácico para a Dieta 1 . Obsevar-se que o peso vivo dos animais nas duas aumentou (Figura 1). Os animais na Dieta 1 entraram com peso vivo de $51,6 \mathrm{~kg}$ e aos 90 dias, alcançaram $87,2 \mathrm{~kg}$, enquanto que os animais da Dieta 2 entraram no experimento com o PV de 47,27 \pm $1,25 \mathrm{~kg}$ e aos 90 dias alcançaram $87,5 \pm 7,5 \mathrm{~kg}$.

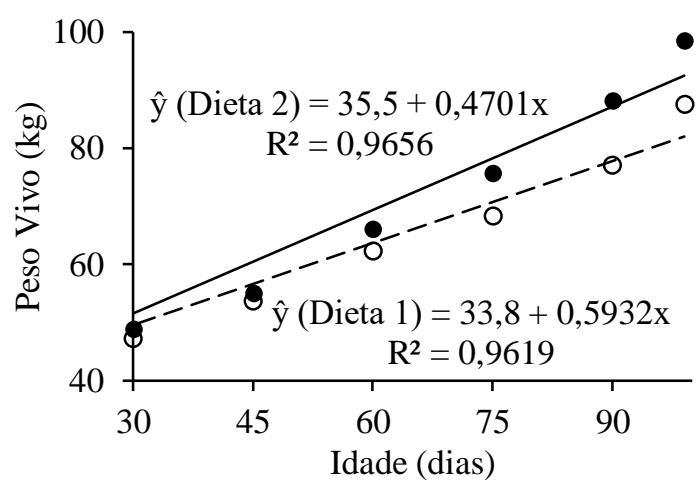

Figura 1 Estimativa do peso de vivo de bezerros Girolando no Brejo Paraibano em função das dietas 1 ( $100 \%$ peletizado) e 2 (50\% peletizado e $50 \%$ feno de tifton).

O ganho de peso nessa fase está ligado ao crescimento, que está diretamente relacionado a dieta. Em termos absolutos observa-se que os animais ganharam mais peso na Dieta 1 , embora não tenha havido diferença estatística $(\mathrm{P}>0,001)$ entre os quilogramas ganhos por estes animais nas duas dietas, visto que todos além dessa dieta estavam recebendo sucedâneo ao longo de todo o experimento.

Esse aumento de peso vivo dos animais da Dieta 1 está relacionado com a alimentação. A partir da segunda semana de vida já é preconizado pela literatura fornecer alimentos sólidos para que os animais comecem a desenvolver as papilas ruminais. Não sendo à toa que grande parte do concentrado para os animais são peletizados, os fabricantes justificam que a ração peletizada além de ter na composição todos ingredientes necessários, evita desperdício e aumenta o 
consumo pelos animais (Gonsalves Neto et al. 2008).

O ganho de peso e desenvolvimento ruminal estão ligados ao consumo de concentrado, onde Arrigoni et al., (2013) relata que rações com teores mais altos de grãos propiciam ganho de peso mais rápido e melhor conversão alimentar. Germano (2018) relata que muito dos trabalhos hoje estudados nos mostram isso, e também tentam solucionar uma dúvida da maioria dos proprietários sobre qual melhor ração a se utilizar na alimentação de bezerros, farelada ou peletizada, mas não há diferença significativa quanto à forma prontificada do concentrado, e sim que este é importante na alimentação (Brittar et al., 2009). Um dos únicos autores que solucionou este questionamento foi Warner (1991) que verificou que animais alimentados com rações em formas grosseiras tem maior desempenho do que os alimentados com ração farelada.

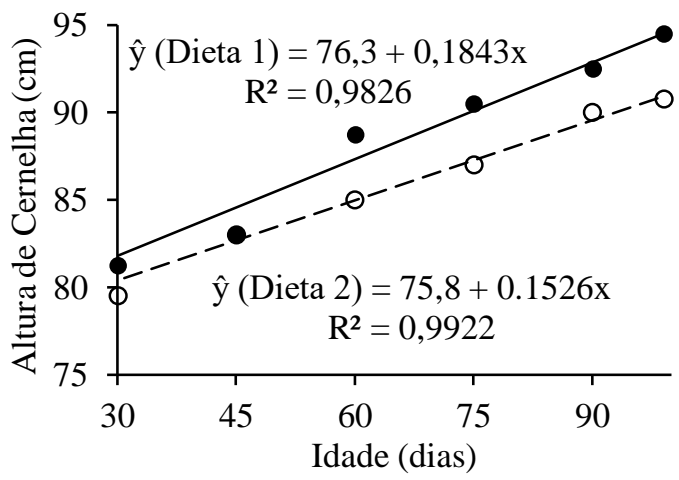

Figura 2 Estimativa da altura de cernelha de bezerros Girolando no Brejo Paraibano em função das dietas 1 ( $100 \%$ peletizado) e 2 (50\% peletizado e $50 \%$ feno de tifton).

Na Figura 2 observar-se que a altura de cernelha em função das Dietas 1 e 2 de bezerros Girolando no Brejo Paraibano não diferiram $(\mathrm{P}>0,001)$. Isso pode ser explicado através de que, os animais estavam em fase de crescimento e como consequência disto a tendência é aumentar a sua altura, como peso vivo e perímetro torácico. Mesmo não havendo diferença estatística entre as Dietas, pode-se observar que ambos tratamentos tiveram um comportamento linear crescente, sem que houvesse um declínio durante o período de avaliação.

Gonsalves Neto et al. (2008) embora trabalhando com duas formas diferentes de concentrado (farelada e peletizada) com inclusão de feno na desmama também não achou diferença significativa nos parâmetros de peso vivo, altura de cernelha e perímetro torácico.

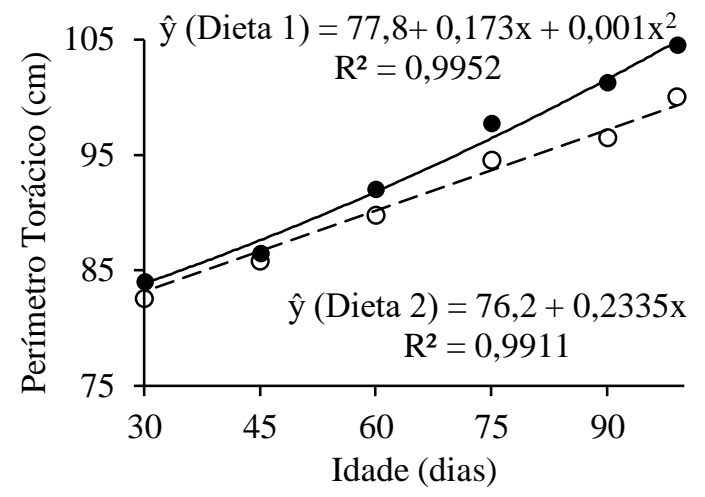

Figura 3 Estimativa do perímetro torácico de bezerros Girolando no Brejo Paraibano em função das dietas 1 (100\% peletizado) e 2 (50\% peletizado e $50 \%$ feno de tifton).

É possível observar a estimativa de perímetro torácico em função das Dietas 1 e 2, onde a Dieta 1 apresentou comportamento quadrático, enquanto que a Dieta 2 apresentou um comportamento linear (Figura 3). Tais resultados devem-se ao maior consumo de alimento dos animais da Dieta 1, que chegaram aos 90 dias com peso máximo de $106 \mathrm{~kg}$ e um perímetro torácico de $107 \mathrm{~cm}$. Além disso a região do Brejo Paraibano possui características específicas de clima, com uma quantidade de chuva elevada do que em outras regiões no estado da Paraíba, que podem também ter favorecido ainda mais o desempenho destes animais, e em específico no ano de 2017, no período do experimento que choveu menos do que o esperado, podendo assim diminuir a incidência de carrapatos e desconforto térmico para animais nessa idade.

Por mais que os animais da Dieta 1 apresentaram diferença significativa em relação aos animais da Dieta 2, é possível ver que o aumento de perímetro torácico dos animais da Dieta 2 foi linear, informando-nos que teve um aumento crescente sem que houve queda, e isso se deve a parte volumosa na dieta, que proporciona maior desenvolvimento de musculatura e expansão ruminal.

Na Tabela 4 é possível visualizar as médias e coeficientes de variação de peso vivo (PV), altura de cernelha (AC) e perímetro torácico (PT). 
Valores próximos as médias de altura de cernelha e perímetro torácico foram encontrados por Gonsalves Neto et al. (2008) foi de $73,72 \mathrm{~cm}$ para altura de cernelha e para perímetro torácico de $87,04 \mathrm{~cm}$, comparadas as duas formas de ração, peletizada e farelada, o que pode justificar essa variação de uma dieta para outra é a ingestão de feno dos animais da Dieta 2, visto que o consumo de feno desenvolve mais o rúmen, fazendo com que haja uma expansão abdominal maior. Já Lima et al. (2012), trabalhando com associação do soro de queijo em associação ao colostro em bezerros mestiços Holandês X Zebu, onde para peso vivo para leite integral foi de 57,74 enquanto que aqui para feno e peletizado foi de 59,82 .

Tabela 4 Dados médios, coeficiente de variação (CV) e probabilidade $(\mathrm{F})$ das mensurações de peso vivo $(\mathrm{PV})$, altura de cernelha (AC) e perímetro torácico (PT) de bezerros da raça Girolando em função de dois tipos de alimentação, ração peletizada (Dieta 1) e ração peletizada e feno de tifton 50:50 (Dieta 2)

\begin{tabular}{llrc}
\hline Dieta & \multicolumn{1}{c}{ Média } & CV (\%) & F \\
\hline \multicolumn{4}{c}{ PV (kg) } \\
1 & 64,48 & 12,52 & 0,0001 \\
2 & 59,82 & 12,31 & 0,0001 \\
\multicolumn{4}{c}{ AC (cm) } \\
1 & 85,81 & 3,27 & 0,0001 \\
2 & 83,72 & 3,47 & 0,0001 \\
& \multicolumn{2}{c}{ PT (cm) } \\
1 & 90,56 & 2,52 & 0,0001 \\
2 & 88,25 & 4,35 & 0,0001 \\
\hline
\end{tabular}

A utilização de alimentação volumosa para animais jovens é um dos motivos de questionamento ainda, visto que proprietários optam por não fornecer volumoso aos animais antes de 60 a 90 dias, mas sabe-se que o volumoso é de suma importância no desenvolvimento da musculatura ruminal, como também na sua movimentação, manutenção e saúde do animal, características essas relacionadas ao consumo de alimentos rico em carboidratos. Animais que tem somente acesso a alimentos concentrados podem sofrer de queda de $\mathrm{PH}$ ruminal, hiperqueratinização das papilas e paraceratose, resultando assim em diminuição na absorção de ácidos graxos voláteis e ingestão de matéria seca (Bernardes et al., 2007).

Rações concentradas também tem suas qualidades nutricionais para os animais, pois são alimentos que são rapidamente fermentados pelos microrganismos ruminais, ocasionando benefícios na aceleração da maturação do retículo-rúmen (Nusio et al., 2003; Nielsen, 2008).

Já o feno tem qualidades que ajudam os bezerros durante a fase lactente, devido ao desenvolvimento dos músculos envolvidos na ruminação e $\mathrm{pH}$ do líquido ruminal serem maiores, consequentemente produzindo maior quantidade de saliva e isto não é consensualmente recomendado (Oliveira et al., 2013). Existindo assim autores que são favoráveis (Zitnan et al., 2005; Oliveira et al., 2007), como também autores que não são favoráveis (Suárez et al., 2007; Khan et al., 2011) a utilização do feno para animais lactentes.

Tabela 5 Custos médios* e totais equivalentes as dietas 1 e 2

\begin{tabular}{lccccc}
\hline Dieta & $\begin{array}{c}\text { Quantidade de } \\
\text { Sucedâneo/dia }\end{array}$ & $\begin{array}{c}\text { Custo Aleitamento } \\
(\mathrm{R} \$)\end{array}$ & $\begin{array}{c}\text { Dieta Sólida } \\
(\mathrm{kg})\end{array}$ & $\begin{array}{c}\text { Custo Dieta } \\
\text { Sólida }(\mathrm{R} \$)\end{array}$ & $\begin{array}{c}\text { Custo Total } \\
(\mathrm{R} \$)\end{array}$ \\
\hline 1 & $4 \mathrm{~L}$ & 377,28 & 99,95 & 152,42 & 529,70 \\
2 & $4 \mathrm{~L}$ & 377,28 & 85,74 & 103,74 & 480,43
\end{tabular}

*Valores referentes ao custo dos insumos em janeiro de 2018. Dieta 1: ração peletizada 100\%. Dieta 2: ração peletizada e feno de tifton 50:50

A Tabela 5 nos mostra todos os custos do experimento com alimentação e o custo total das Dietas 1 e 2, respectivamente. O preço de um litro de sucedâneo estava a $\mathrm{R} \$ 1,048$ foi multiplicado aos 4 litros que estes animais consumiam diariamente e multiplicado por 90 que foi a quantidade de dias que os animais passaram ingerindo $\mathrm{o}$ sucedâneo durante todo $\mathrm{o}$ experimento, isso equivale ao total de $\mathrm{R} \$ 377,28$.

A quantidade em quilogramas que os animais da Dieta 1 e 2 consumiram em média durante os 90 dias foi obtido através da somatória de todo o consumo dos quatro animais que de cada dieta no total e dividido por 4. Para o custo das dietas 
sólidas foi pego o valor em quilogramas da dieta sólida e multiplicado por o valor (de um quilo) de cada dieta. Onde a Dieta 1 o valor do quilo do peletizado estava a $\mathrm{R} \$ 1,525$ e o valor do quilo da Dieta 2 estava de $\mathrm{R} \$ 1,21$ para feno de tifton somado com peletizado.

A Dieta 1, como pode ser visto, saiu $\mathrm{R} \$ 49,27$ mais cara do que a Dieta 2, isso porque o feno de Tifton utilizado tem um preço menor em relação ao preço do peletizado.

Além do peletizado pode ser visto que o sucedâneo foi um dos componentes com maior custo, isso se deve ao fato de que os animais durante essa fase necessitam de uma fonte de alimentação principal que é o leite. $\mathrm{O}$ sucedâneo representa uma economia de 0,95 centavos em relação ao leite de vaca na região de Areia-PB (correspondente ao valor do litro de leite em janeiro de 2018), significando assim que essa substituição é satisfatória para o sistema em questão.

Foi feito o custo somente das dietas e sucedâneo, pois em relação a mão de obra e aquisição de animais não se fez necessário já que os animais eram advindos da própria Universidade e a mão de obra feita por alunos da mesma, o que não implica desse sistema poder ser implantado em pequenas propriedades, onde o trabalhador da fazenda que faz o manejo da ordenha consegue realizar essa tarefa com os bezerros.

As dietas apresentaram um custo relativamente bom, em virtude de o consumo destes animais terem sido satisfatórios, já que os mesmos estavam sendo aleitados e o que se tem visto é que animais que são aleitados durante a fase de cria tem um baixo nível de consumo de dieta sólida e só após o desaleitamento que a ingestão começa a crescer.

\section{Conclusão}

A substituição de $50 \%$ do concentrado por feno não afeta o desenvolvimento de bezerros no período de 30 a 90 dias de idade e contribui para reduzir os custos com alimentação.

\section{Referências}

Arrigoni, M. D. B.; Martins, C. L.; Sarti, L. M. N.; Barducci, R. S.; Franzói, M. C. S.; Vieira Júnior, L. C.; Perdigão, A.; Ribeiro, F. A.;
Factori, M. A. Níveis elevados de concentrado na dieta de bovinos em confinamento. Veterinária e Zootecnia, v. 20, n. 4, p. 539551, 2013. http://hdl.handle.net/11449/141034

Bernardes, E. B.; Coelho, S. G.; Carvalho, A. U.; Oliveira, H. N.; Reis, R. B.; Saturnino, H. M.; Silva, C. A.; Costa, T. C. Efeito da substituição do feno de Tifton 85 pelo caroço de algodão como fonte de fibra na dieta de bezerros. Arquivo Brasileiro de Medicina Veterinária e Zootecnia, v. 59, n. 4, p. 955964, 2007. http://dx.doi.org/10.1590/S010209352007000400022

Ferreira, F.; Barbosa, K.; Sene, G.; Jayme, D. Avaliação do consumo e peso de bezerros da raça girolando alimentados com concentrado farelado ou peletizado durante a fase de aleitamento. In Anais ... II Seminário Iniciação Científica - IFTM, Campus Uberaba, 2009. http://www.iftm.edu.br/pesquisa/revista_2/resumo/zootec nia/resumo8.pdf

Gomes, N. J. G. Substituição parcial do concentrado por feno de tifton na alimentação de bezerros girolando. 2018. 41f. (Graduação em Zootecnia) - Centro de Ciências Agrárias, Universidade Federal da Paraíba, Areia, 2018. https://repositorio.ufpb.br/jspui/handle/123456789/3436

Gondim, A. W. A.; Fernandez, B. Probabilidade de chuvas para o município de Areia-PB. Agropecuária Técnica, v. 1, n. 1, p. 55-63, 1980. https://doi.org/10.25066/agrotec.v1i1.43446

Gonsalves Neto, J.; Silva, F. F.; Bonomo, P.; Nascimento, P. V. N.; Fernandes, S. A. A.; Pedreira, M. S.; Velloso, C. M.; Teixeira, F. A. Desempenho de bezerros da raça Holandesa alimentados com concentrado farelado ou peletizado. Revista Brasileira de Saúde e Produção Animal, v. 9, n. 4, p. 726-733, 2008. http://revistas.ufba.br/index.php/rbspa/article/view/1102/ 702

Gonsalves Neto, J. Manual do Produtor de Leite. $1^{a}$ ed. Aprenda Fácil Editora, 2012. 558p.

Khan, M. A.; Weary, D. M.; Von Keyserlingk, M. A. G. Invited review: Effects of milk ration on solid feed intake, weaning, and performance in dairy heifers. Journal of Dairy Science, v. 94, n. 3, p. 1071-1081, 2011. https://doi.org/10.3168/jds.2010-3733 
Lima, R. N.; Oliveira, P. L.; Aroeira, L. J. M.; Miranda, M. V. F. G.; Lima, K. T. L.; Diógenes, G. V.; Rossato, C. H. Desempenho de bezerros aleitados com soro de queijo em associação ao colostro. Pesquisa agropecuária brasileira, v. 47, n. 8, p. 1174-1180, 2012. http://dx.doi.org/10.1590/S0100-204X2012000800019

Nielsen, Per Peetz. Behaviours related to milk intake in dairy calves. 2008. 53f. Swedish University of Agricultural Sciences.

Oliveira, A.A.; Azevedo, H.C.; Melo, C.B. Criação de bezerras em sistemas de produção de Leite. Aracajú: Embrapa Tabuleiros Costeiros, 2005. 8p. (Circular Técnica, $38)$. http://www.cpatc.embrapa.br/publicacoes_2005/ct-38.pdf

Oliveira, D. P.; Oliveira, M. V. M.; Vargas Júnior, F. M.; Luz, D. F.; Simões, A. R. P.; Oliveira, C. A. L.; Braga Netto, A. L.; Silva, S. C. C. Desempenho de bezerros leiteiros lactentes alimentados com feno. Archivos de zootecnia, v. 62, n. 239, p. 357-367, 2013. http://dx.doi.org/10.4321/S0004-05922013000300004

Oliveira, D. J. C. de; Nogueira, G. Curvas de crescimento de bezerros da raça girolando. Arquivos de ciências veterinárias e zoologia da UNIPAR, v. 9, n. 1, p. 3-8, 2006. https://doi.org/10.25110/arqvet.v9i1.2006.31

Oliveira, J. S.; De Moura Zanine, A.; Santos, E. M. Fisiologia, manejo e alimentação de bezerros de corte. Arquivos de Ciências Veterinárias e Zoologia da UNIPAR, v. 10, n. 1, p. 39-48, 2007. https://doi.org/10.25110/arqvet.v10i1.2007.571
Owens, F. N.; Dubeski, P.; Hanson, C. F. Factors that alter the growth and development of ruminants. Journal of Animal Science, v. 71, n. 11, p. 3138-3150, 1993. https://doi.org/10.2527/1993.71113138x

SAS. 2010. Statistical Analysis System Institute. Institute SAS/STAT software, CDROOM.

Suárez, B. J.; Van Reenen, C. G.; Stockhofe, N.; Dijkstra, J.; Gerrits, W. J. J. Effect of roughage source and roughage to concentrate ratio on animal performance and rumen development in veal calves. Journal of Dairy Science, v. 90, n. 5, p. 2390-2403, 2007. https://doi.org/10.3168/jds.2006-524

Valadares Filho, S. C.; Machado, P. A. S.; Furtado, T.; Chizzotti, M. L.; Amaral, H. F. Tabelas Brasileiras de Composição de Alimentos para Ruminantes. Viçosa: Editora UFV, 2015. 38p.

Warner, R. G. Nutritional factors affecting the development of a functional ruminant: A historical perspective. In: Cornell Nutrition Conference for Feed Manufacturers (USA). 1991.

Zitnan, R. Kuhla, S.; Sanftleben, P.; Bilska, A.; Schneider, F.; Zupcanova, M.; Voigt, J. Diet induced ruminal papillae development in neonatal calves not correlating with rumen butyrate. Veterinarni Medicina, v. 50, n. 11, p. 472-479, 2005. https://doi.org/10.17221/5651VETMED 